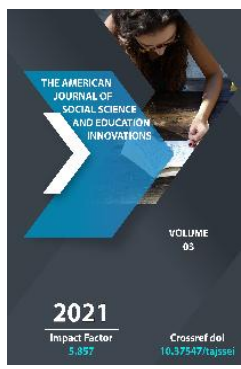

\title{
Principles And Practices Of A Language Assessment
}

\author{
Inomkhojaeva Shodiyakhon Abdqodirhoja Qizi \\ Teacher, Department Of Practical English, Uzbek State University Of World Languages, \\ Tashkent Uzbekistan
}

\begin{abstract}
Journal Website:
http://theamericanjour

nals.com/index.php/taj

ssei

Copyright: Original content from this work may be used under the terms of the creative commons attributes 4.0 licence.
\end{abstract}

\section{ABSTRACT}

Evaluation has a critical part in instruction and it features a basic part within the instructing prepare. Through fitting evaluation, instructors can classify and review their understudies, deliver criticism and structure their educating appropriately. As of late, teachers and scientists have been getting to be more fascinated by the necessities of evaluation methods within the scope of outside dialect educating and the learning handle, as forms of evaluation have been changing. The evaluation strategies relate to authenticity, common sense, unwavering quality, legitimacy and wash back, and are considered the essential standards of appraisal in remote dialect instructing and learning. The most esteem of these previously mentioned standards is to recognize the impacts of appraisal and audit any classroom based issues between the instructor and the understudy. As the evaluation prepare influences both instructors and understudies, centrality and thought ought to be given to appraisal strategies in outside dialect educating.

\section{KEYWORDS}

Evaluation, ipsative, summative, formative, computer-based, electronic grading.

\section{INTRODUCTION}

In the field of education, there are several types of evaluations. All evaluation methods have different uses. This article will tell you the most important types of assessments when developing and implementing your training.

According to the Anderson there are 7 types of assessments that every test taker should know. They are pre-assessment or diagnostic 
assessment, formative assessment, summative evaluation, certification evaluation, normative assessment, criteria evaluation and ipsative evaluation. (Anderson , L. W., 2001).

\section{Types of assessment}

Pre-assessment or diagnostic assessment. Before creating a course, it is essential to know what type of students it is aimed at. Your goal is to know their strengths, weaknesses, knowledge and abilities before they start it. You can then create your training based on the data collected.

Formative assessment. Formative assessment is used during the first training attempt. Its purpose is to monitor student learning and obtain feedback in order to identify teaching gaps. This feedback thus makes it possible to know what to focus on in order to continue the training.

Summative evaluation. The summative evaluation aims to assess whether the most important knowledge has been acquired at the end of the training. It can also assess much more than that, since it measures the effectiveness of learning, student reactions to the training, and long-term benefits (the latter can be determined by monitoring students who participated in your training or test). This allows you to see how they have used their skills and knowledge.

Certification evaluation. Once your training has been implemented in your classroom, it is essential to do an assessment. The certification assessment allows you to find out whether the training is still working and whether, for example, your teaching method is still suitable. To some extent, it can be said that certification evaluation is a more extensive form of summative evaluation.
Normative assessment. This is used to compare a student's performance to an average standard. This may very well be a national standard (or rating) for a particular topic (such as, eg, history). Another example of this type of assessment is comparing a student's grades with the average grades for the entire school.

Criteria evaluation. It is used to measure the performance of a student according to predefined criteria. It checks that students have the expected knowledge expected at a specific stage of their education. Criteria assessments are used to assess a particular set of knowledge or skills: it is a test that assesses the curriculum being taught.

Ipsative evaluation. This type of assessment measures a student's performance in relation to their past performance. This method aims to encourage the student to improve. However, since he does not compare himself to other students, this can have a detrimental effect on his self-confidence.

Evaluation methods and strategies. If you want to create an assessment on what you have taught, this article will offer you some methods and strategies to improve your assessment.

Rao $\mathrm{K}$ claims that there are different evaluation methods that can be used for different purposes. First, you need to know what type of assessment to use based on what you are teaching. To make it easier for you to choose the type of assessment, consult this page.

Writing an assessment can be a difficult task. There are some rules that will help you improve your assessments and get the best from your students (RAO, K., 2016). 
Avoid terms such as "always" and "never" These terms are almost never the right answers. Moreover, the participants know it very well. You are not trying to test whether participants know all the tips for answering questions. What you want is to test their knowledge.

\section{Avoid double negations}

"Which of the following is NOT incorrect?" You have to read the question three times before you can understand its meaning. So it is better to ask "Which of the following is correct?" It means exactly the same thing, except it's much easier to understand!

\section{Ask positive questions instead of negative}

A negative question challenges its reader to understand it correctly. Avoiding these kinds of questions means less stress for the participants. It's also much less confusing. Give 4 to 5 answer choices. Experts recommend giving four or five answer options. Are you doing well what the experts say?

\section{Ask open-ended questions}

In some cases, it is easier to ask yes or no questions. In other cases, it is not very practical. Indeed, you may have questions relating to the understanding of the instructions. If a student says they didn't understand the instructions, you might want to know why they didn't understand. A free answer question solves this problem.

\section{Use our online assessment tool}

Using an online assessment tool makes it easier for you to collect data on your students. When you teach a large group, you want a large percentage of that group to pass the assessment. Our tool lets you do it all! The person creating the assessment can ask all kinds of questions and then can export all the data as an Excel file.

\section{What are the principles and practices of the} evaluation?

Coe R. explains the principles of evaluation are the basic propositions considered important for the design, the implementation, correction and grading of assessments leading to diplomas and certificates. They derive from the essential elements of the IB education system, the overriding principle being that assessments should serve education, not distort it . (COE, R., 2008)

The practices of evaluation are the effective and concrete transposition of the principles. They hold account of the conflicting requirements and practical limits posed by use across the world, while respecting integrity.

The practices of the evaluation are described in a very general way and they must be put in works adequately, depending on the context specific to each subject, discipline and program (COE, R., 2008). They generally explain what needs to be done, without giving specific details on how to walk, monitor on a daily basis or on different applications depending on the materials concerned. 


\section{educational}

\section{objectives}

learning

objectives assessment

design

Figure 1. Link between educational objectives, learning objectives and assessment design used for the assessment. In fact, it will usually be easier to

\section{A technology-based assessment}

Schleicher acknowledges that The students make very extensive use of technology. They use it for example in their social life, but also for their learning and writing their essays. (Schleicher, A., 2016) Why their do we still ask to write their exams by hand? Scientists claim that it is better to use technology to improve the quality of its assessments and make them more relevant. Technology will not influence the assessment approaches that are chosen. It is important to distinguish between the effects of technology in providing support for specialist examiners (electronic scoring) and use of technology to design relevant assessments for students (computer-based assessment - to both for exams and for internal assessment - and electronic portfolios). The one should not confuse the expressions "on computer" and "online": no connection Internet skills will not be required in order to take the IB assessments. This connection does will be required once the assessments are complete, to send the electronic files. Students should have learned in class how to use the technology that will be get them used to this technology by means of a teaching than directly during an assessment.

\section{What does the computer assessment look like?}

As the name suggests, computer-based assessment simply means an assessment performed on a computer (Schleicher, A., 2016). This does not involve multiple choice or drag and drop (to unless the situation lends itself to it). First, the idea is to use computers while maintaining the style of the current exam papers. Subsequently, improvements will be made to assessments by including interactive questions that will give exams more authenticity or make them more accessible to students. The potential offered by evaluations on computer has already started to be crawled in the PEI, but slower adoption was chosen for the Diploma Program. The following video presents examples of questions that may be to be asked in computer-based assessments. 
From a practical standpoint, taking computerbased assessments means that each candidate must have a computer for the exam. No internet connection is required, however, since the tests are loaded onto the computers before the exams start. With the model currently used for the IEP, the computer is "locked" for the duration of the use of the examination software and backups are made at the slightest interruption (the supervisor can restart in the event of a justified interruption of the examination).

Schleicher A. explains the Computer-based assessment has considerable advantages: it allows to test what one genuinely wants to test and not just what is possible with a paper exam. All details are in the section on benefits for validity, but just to name a few a few simple examples, this system allows the use of video supports, offers candidates the ability to rotate and move diagrams, but also to use the tools of common word processors to write their essays. In the section "Fairness for all: meet the needs of candidates ", it is explained that the computer-based assessment can strengthen accessibility, by giving applicants the ability to change the colors and size of the font as well as using tools like screen readers (Schleicher, A., 2016).

Finally, the computer-based assessment will not be static. The evaluations may indeed evolve with technological advances. Currently, only the use of keyboards and mice or touchpads is taken into account, but in a few years it is very likely that the touch screens will be commonplace and will open up new horizons. By pushing the reflection even further, what could be the place of virtual reality in certain evaluations? Such environment could give even more authenticity to foreign language assessments, and science fiction films are a favorable framework for the development of ideas on how to manage technical tasks (scientific questions) in virtual reality laboratories (Schleicher, A., 2016).

\section{What is electronic grading?}

The term "electronic grading" is used to designate the work grading system candidates using computers to view papers and record notes. Without exception, examiners no longer receive exam papers or internal assessment assignments in the paper: the whole is digitized so that examiners can access the digital format in connecting to the Internet and using specialized scoring software.

\section{This system has major advantages in terms of speed and quality of scoring.}

- The system of electronic grading keeps the candidates' work in its possession. Therefore, if this work needs to be reviewed, for for whatever reason, by a second examiner, he is then immediately available and not subject to the delays imposed by a shipment to another country.

- Candidates' work can be made anonymous in order to reduce the risk of bias in the examiner's rating.

- A more rigorous quality control process can be implemented with verification grading standards as the marking progresses.

- The work of candidates from the same institution can be distributed among all reviewers, instead of all being graded by one reviewer. Quality control can thus to be pushed even further.

Risks to avoid with computer-based assessment. 
Developing a computer-based assessment first requires being aware of a certain number of significant difficulties, and then overcome them to ensure equity between all applicants and all institutions. Some of the main risks to be managed are listed in the following list. Further analysis will be carried out in several sections of this document, as well as in other IB publications on e-assessment laboratories (Schleicher, A., 2016).

\section{The burden on establishments.}

It must be recognized that the use of technology is now perfectly integrated into the daily actions of students. Therefore, asking them to write on paper would be an anachronistic requirement. The fact remains that institutions need time to change their practices and that computer-based assessments require adjustments. Particular compared to paper-based exams. The introduction of computer-based assessments will be done carefully at the Diploma Program and POP level, so that all institutions can keep up with technological advances, but also so that they do not have to adapt too abruptly, regardless of their location.

\section{The risk of technological failure.}

No degree of technological failure can be accepted when it comes to the passage of exams. Indeed, each candidate is entitled to experience this event smoothly. To achieve this, two principles are followed. First, the assessment can be taken on a single computer and no internet connection is required. Second, institutions have the opportunity to complete a full testing or compliance process the day before exams. Experience shows in fact most of the problems come from the infrastructure or from certain parameters of the establishments, which can therefore be spotted and resolved well in advance of exams

\section{Security issues.}

The security level for computer-based assessments must be at least the same as for exams on paper. These assessments are designed to 'lock in' all other functionality of the computer while they are running. They are also encrypted and protected by a password.

Even though the security needs to be constantly reinforced, due to the developments of more in addition to the more sophisticated that are emerging, we must not lose sight of the fact that the paper examinations used they are also currently exposed to certain risks.

\section{CONCLUSION}

Testing concerning evaluations can give both instructors and understudies with data almost the level of information, aptitudes, troubles in remote dialect learning and which exercises and strategies are the foremost useful. Testing could be a implies of assessment of understudy exercises and can be utilized for a clear model or scale. The word appraisal implies the consideration of a individual and an assessment of them, and contains a more extensive basis than testing (Akpinar \& Cakildere, 2013; Brown, 2004), which can be utilized with the things, to test, degree and assess. Within the light of elective evaluations, instructors may distinguish what is critical in their instructing handle and select appraisal techniques reasonable for the characteristics of the learners. Knowing and organizing standards of appraisal, creates the arranging of evaluation of a outside dialect.

\section{REFERENCES}


1. Akpinar, K., \& Cakildere, B. (2013). Washback effects of high-stakes language tests of Turkey (KPDS and ÜDS) on productive and receptive skills of academic personnel. Dil ve Dilbilimi Çalışmaları Dergisi, 9(2).

2. Anderson, L. W., \& Bloom, B. S. (2001). A taxonomy for learning, teaching, and assessing: A revision of Bloom's taxonomy of educational objectives. Longman.

3. Brown, H. D., \& Abeywickrama, P. (2010). Language assessment: Principles and classroom practices (Vol. 10). White Plains, NY: Pearson Education.

4. Coe, R., Searle, J., Barmby, P., Jones, K., \& Higgins, S. (2008). Relative difficulty of examinations in different subjects. Durham: CEM centre.

5. Rao, K., Currie-Rubin, R., \& Logli, C. (2016). UDL and inclusive practices in IB schools worldwide. CAST Professional Learning, 136.

6. Schleicher, A. (2016). Advocacy for modern education [online]. OECD, Reference Accessed January 1, 2017., 72-90. 